\title{
SERÃO EXPLICÁVEIS OS CONFLITOS VIOLENTOS EM ÁFRICA? NOTAS DE LEITURA
}

ISABEL MEDEIROS ${ }^{1}$

\begin{abstract}
Resumo - A maior parte dos países africanos, na sequência das independências políticas, e sobretudo no período pós Guerra Fria, num contexto de crescente globalização, tem conhecido situações de turbulência política que por vezes culminaram em massacres e confrontos de grande violência. Para muitos autores as guerras civis que se desencadearam ou ressurgiram na década de 90 correspondem a um tipo "novo" de conflito, embora não seja consensual separar "novas" e "velhas" guerras. Na perspectiva do alcance da paz e da respectiva prevenção é essencial aprofundar o conhecimento das causas subjacentes a cada situação nas suas complexas e múltiplas interligações. Neste texto analisam-se diferentes posições doutrinais sobre o assunto, considerando-se em particular os casos do Sudão, da Costa do Marfim e do Uganda. Também são objecto de comentário as relações entre guerra, fome e insegurança alimentar e as de género, atendendo sobretudo à situação das mulheres combatentes.
\end{abstract}

Palavras-chave: África, conflitos violentos, globalização, insegurança alimentar, relações de género.

\begin{abstract}
Can violent conflicts in Africa Be explained? Notes from the LITERATURE After political independence - and especially in the context of accelerating globalisation that followed the end of the Cold War -, most African countries have been affected by political instability, sometimes culminating in violent civil wars and massacres. In the current scientific debates, the wars of the 1990's and 2000's have been singled out and characterised by some authors as "new wars". However, there is considerable controversy surrounding this distinction between "old" and "new" wars. The causes of African conflicts are complex and multidimensional. From a conflict prevention and resolution perspective, it is essential that our understanding of African conflicts be improved through further analyses of the root causes of conflict, as well as of their complex and multiple interactions over time. This paper discusses some of the main doctrinal and theoretical perspectives on this topic, with particular reference to the cases of the Sudan, Côte d'Ivoire and Uganda. The linkages between war, hunger and food insecurity, and gender relations are also examined, namely as regards the situation of women combatants.
\end{abstract}

Recebido: . Aceite: 29/07/2009. Aceite: 10/11/2009

1 Investigadora do Centro de Estudos Geográficos. E-mail: isamede@gmail.com 
Key words: Africa, violent conflicts, globalization, food insecurity, gender and war.

Résumé - COMMENT EXPLIQUER LES CONFLITS VIOLENTS QUI AGITENT L'AFRIQUE ? Notes DE LECTURE. À la suite des indépendances et principalement après la fin de la Guerre Froide, dans un contexte de mondialisation croissante, la plupart des pays africains ont connu des situations de turbulence politique ayant parfois provoqué des massacres et des confrontations de grande violence. Beaucoup d'auteurs affirment que les guerres civiles qui ont surgi ou ressurgi dans les années 90 correspondent à un "nouveau" type de conflit, bien qu'on ne s'accorde guère sur la différence entre "nouveaux" et "anciens" conflits. Afin de rétablir la paix et de prévenir les conflits, il est important de mieux connaitre les causes sous-jacentes aux diverses situations, ainsi que les complexes liaisons entre elles. On analyse ici divers points de vue sur ce sujet, en particulier les cas du Soudan, de la Côte d'Ivoire et de l'Ouganda. On commente aussi les rapports qui existent entre la guerre, la faim et l'insécurité alimentaire, ainsi que les problèmes liès au "genre", en traitant surtout celui des femmes combattantes.

Mots-clés: Afrique, conflits violents, globalisation, insécurité alimentaire, relations entre les sexes.

\section{INTRODUÇÃO}

Sem considerar a conflituosidade que percorreu o continente, precedendo o desmantelamento dos impérios coloniais, é um facto que, na sequência das independências políticas e até hoje, num espaço de quase meio século, a maior parte dos países africanos tem conhecido, ao longo do tempo (e em particular, no período pós Guerra Fria), situações dolorosas, mais ou menos prolongadas, mais ou menos recorrentes, de tensão e turbulência política e social (movimentos de contestação popular, golpes militares, guerras civis, rebeliões de grupos mais ou menos organizados que ora estabilizam ora desencadeiam hostilidades no âmbito da luta de guerrilha...), por vezes culminando em massacres e confrontos de grande violência.

Bouquet (2008) menciona que dos 35 conflitos violentos identificados no mundo, 13 se situavam em África; também na mesma data, cerca de $70 \%$ das decisões da ONU e do Conselho de Segurança diziam respeito ao continente... Esta realidade, largamente mediatizada, foi e continua a ser um dos aspectos que, em conjunto com outros, tais como pobreza, fome, expansão da infecção pelo vírus HIV/Sida, catástrofes naturais, confere maior visibilidade às "Áfricas" e aos africanos, difundindo e alimentando uma visão catastrófica, redutora e afro pessimista.

Embora nos últimos anos se tenham reduzido o número de ocorrências e registado alguns progressos em matéria de resolução e de alcance da paz (não obstante persistirem situações de conflito endémico, como ainda se verifica na República Democrática do Congo - RDC), as suas consequências cumuladas são incalculáveis, dramáticas e devastadoras. A violência provoca milhares de vítimas, directas e indirectas: estimouse, por exemplo, que, naquele país, a guerra civil desencadeada no leste, em Outubro de 1996, tenha dizimado cerca de $7 \%$ da população; na do Ruanda quase 1 milhão ${ }^{2}$. 
Mas também gera pobreza, abandono de terras, de animais, de culturas, problemas alimentares, fome, aspectos que se espelham a uma escala bem mais ampla do que a do local do confronto, minando as reais possibilidades de progresso socioeconómico das populações. Destroem-se habitações, infra estruturas, equipamentos, desestruturamse famílias, perdem-se laços de coesão e relações de confiança, há milhões de deslocados, populações em fuga, traumatizadas por rapto e recrutamento forçado de crianças e de mulheres...Pode afirmar-se que os conflitos violentos exacerbam as condições que à partida os podem ter provocado, criando uma espécie de armadilha de que é difícil escapar, um ciclo vicioso de destruição e empobrecimento que, por sua vez, alimenta mais violência.

O interesse pessoal pelas problemáticas do desenvolvimento e da cooperação condicionou o aprofundamento da questão dos conflitos armados à escala do continente, sobretudo aqueles que surgiram nos últimos 20 anos. No âmbito de trabalho de campo, desenvolvido no norte de Moçambique, relacionado com processos de avaliação participativa das carências mais sentidas pelas populações, a referência recorrente à segurança, no espaço do quotidiano, evidenciou-se como condição prioritária e de maior significado na luta contra a pobreza, mais do que o acesso a serviços, a bens públicos, tais como a educação ou a saúde. Embora a questão securitária tenha ganho grande relevância no quadro geopolítico pós 11 de Setembro de 2001, é um facto que, à escala local, partindo das respostas dadas aos inquéritos realizados, os efeitos da guerra civil que destabilizou o país (acordos de paz em 1992), deveriam ainda estar bem presentes.

Generalizando, considera-se que, nas regiões afectadas por conflitos, urge encontrar a paz, conseguir a reconciliação entre partes em confronto, quando se reclama a necessidade de cumprir os "Objectivos de Desenvolvimento do Milénio". Todavia há que ir mais além, no sentido da estabilização social, da liberdade política e do desenvolvimento económico, cujas fórmulas estão em constante experimentação, sobretudo na sua adaptação aos contextos africanos.

Numa perspectiva geográfica, de geopolítica - "tudo o que diz respeito a rivalidades de poderes ou de influências sobre territórios e as populações que neles vivem: rivalidades entre poderes de vários tipos - não só entre estados mas também entre movimentos políticos e grupos armados mais ou menos clandestinos - e rivalidades pelo controlo ou dominação de territórios de maior ou menor dimensão" (Lacoste, 2006: 8) - importa salientar que, dada a grande diversidade do continente e a evolução das conjunturas, os conflitos registados nas últimas décadas recobrem realidades muito diversas. $\mathrm{Na}$ perspectiva da sua prevenção e resolução, não obstante as grandes dificuldades sentidas, há que ponderar as respectivas especificidades geográficas, procurando detectar quais as causas mais ou menos próximas, os impulsos ou factores actuantes na sua durabilidade e reprodução. Neste plano todos correspondem a situações únicas, com histórias e geografias singulares, pelo que quaisquer interpretações generalistas serão sempre redutoras, embora possa haver pontos comuns.

Mas será possível compreender a guerra?

O presente texto, em que se reúnem reflexões várias, feitas sobre o tema ao longo de anos, tomou como ponto de partida a leitura de um trabalho, coordenado por A. Nhema e P. Zeleza, datado de 2004, mas apenas publicado em 2008, The Roots of African Conflicts. The causes and the costs que, por puro acaso, encontrámos no expositor de uma livraria, amplamente guarnecido de livros sobre questões africanas. Trata-se da primeira parte duma obra, complementada com um segundo volume, The resolution of African Conflicts: the Management of Conflicts resolution \& Post Conflicts Reconstruc- 
tion, realizada no âmbito do Programa de Investigação sobre conflitos africanos da OSSREA (Organização para a Investigação em Ciências Sociais na África Oriental e Austral), na sequência de uma conferência internacional realizada em 2004 em Adis Abeba.

Organizado em 9 pontos (acompanhados de extensa bibliografia em língua inglesa), além da introdução e do prólogo, reúne em 244 páginas contribuições de vários autores, expressando posições por vezes bastante antagónicas e passíveis de controvérsia que denunciam olhares diferentes sobre as realidades sociais africanas.

\section{O FIM DO MUNDO BIPOLAR E AS FALSAS ESPERANÇAS DE PAZ}

Na viragem da década de 90, com o fim da Guerra Fria, parecia possível desanuviar as tensões políticas subjacentes a muitos dos conflitos existentes.

Se num primeiro tempo, nalguns casos, as esperanças pareciam confirmar-se pelos factos - fim do "apartheid" na África do Sul, independência da Namíbia, retirada do cubanos de Angola, acordos de paz em Moçambique - noutros a instabilidade permaneceu, como no Sudão e no Uganda, ou mesmo recrudesceu, como na região dos Grandes Lagos, mencionada por muitos autores como a "primeira guerra pan-africana" (Marchal, 2008); por outro lado, na África Ocidental, citada nos anos 80 como pólo de estabilidade, eclodiram confrontos armados de grande violência: basta citar, entre outros, os que se sentiram na Libéria e na Serra Leoa.

Esta constatação veio contrariar as expectativas da comunidade internacional e de muitos africanos nas possibilidades oferecidas pela dita "abertura" democrática, na altura praticamente imposta pelas instituições internacionais e países credores, para garantir a paz, a estabilidade, o desenvolvimento... Argumentava-se que a realização de eleições multipartidárias seria condição necessária (mas não suficiente) para lutar contra governos corruptos, centralistas, fundamentados numa acumulação "rendeira". Esperava-se que, com a participação da sociedade civil e novas formas de governança, fosse possível o alargamento das oportunidades de acesso ao "bem-estar" de toda a população, de forma equitativa e em plena liberdade... Todavia, esquecia-se (ou subestimava-se) que a democracia tem de surgir a partir de dentro, não é compatível com estados frágeis (sem fiscalização e instituições que promovam avaliação de contagens os processos eleitorais podem ser facilmente explorados por elites ambiciosas), com situações de pobreza extrema e de exclusão e não funciona quando as forças competindo pelo poder, são motivadas por interesses de natureza individual, regional, clânica ou religiosa.

O impacto positivo anunciado revelou-se, em vários países, largamente defraudado. Em muitos deles os novos governos saídos de eleições que, com frequência, consagraram nas urnas os líderes do passado, foram ou ainda são contestados internamente na sua legitimidade. Tal contestação reflecte a manifestação, por parte de determinados grupos da população, de sentimentos reais, ou manipulados, de exclusão, de discriminação, de subordinação a interesses particulares, não sendo raro que provoquem a eclosão de conflito armado, por vezes duradouro e violento (refiram-se, por exemplo, o caso de Angola pós 1991 e o de Madagáscar a seguir à primeira volta da eleição presidencial de 2001).

É importante lembrar também que a dita "abertura democrática" ocorreu num momento em que a maior parte dos países africanos se confrontava com elevadas dívi- 
das externas, se reduziam os montantes da "ajuda internacional" e faziam sentir os duros efeitos das reformas negociadas com as instituições de Bretton Woods. A aplicação dos programas de ajustamento estrutural (PAE), condicionadores da liberalização e privatização das economias, criou profundo mal-estar social, e enfraqueceu substancialmente a capacidade dos Estados (até então presentes em todos os sectores da vida económica e social dos respectivos países) para fazer face às necessidades fundamentais das populações e sustentar as redes clientelistas (que asseguravam em parte a sua legitimidade) (Ferreira, 2001), minando o respectivo poder simbólico.

Neste contexto assistiu-se à emergência de toda a espécie de reivindicações, políticas e económicas, ao aparecimento de uma multiplicidade de novos actores em competição pelo acesso aos recursos, à explosão do sector "informal" no quadro de estratégias de sobrevivência e de reprodução social. O "país real”, expressão citada por Bayart (1989), escapava-se assim, cada vez mais, a qualquer controlo...enquanto o "país legal", de base cada vez mais estreita, continuava a ser o interlocutor privilegiado dos doadores internacionais (Brunel, 2004: 83). Condicionando a prestação da ajuda à diminuição das despesas públicas e à limitação das funções económicas do estado, revelaram não compreender o seu carácter "patrimonial" do Estado em África. Este, para conseguir subsistir e manter a sua limitada base de apoio, teve de se "criminalizar", isto é, desenvolver dinâmicas de acentuada patrimonialização e cleptocracia (Bayart et al., 1997), o que se saldou numa deriva para a informalização das sociedades políticas.

Como seria possível mostrar as vantagens da participação democrática quando, para a maior parte das famílias, as condições de vida se agravaram, a insegurança e a criminalidade progrediram, a falta de confiança nas instituições públicas aumentou e as frustações cresceram?

\section{EXPLICAÇÔES E IDEIAS FEITAS SOBRE AS CAUSAS DOS CONFLITOS EM ÁFRICA...}

A produção de informação sobre a problemática dos conflitos em África é imensa. Quase sempre acompanhada de interpretações simplistas e mesmo pouco correctas, em que se confundem causas com efeitos, tem contribuído para uma série de ideias feitas, na base de falsas evidências. Lendo os jornais, vendo as notícias televisivas e as imagens que as acompanham, as referências mais frequentes acentuam a importância das "questões étnicas", de "antigas" rivalidades tribais ou religiosas; estar-se-ia perante formas de violência gratuita, uma espécie de ressurgimento de nova "barbárie", relativamente à qual a comunidade internacional pouco ou nada tinha a ver.

Sem se negar a importância dos "etnicismos ou de outras fracturas identitárias como as de natureza religiosa, estes aspectos mascaram frequentemente realidades bem mais complicadas: por exemplo, no caso da guerra do Ruanda, associada quase sempre à abertura de feridas não cicatrizadas nas relações históricas entre Tutsis e Hutus (subestima-se que Hutus massacraram outros Hutus e não unicamente Tutsis), raramente se alude à existência de oposições fortes quanto à posse da terra, em contextos de pressão demográfica ou, melhor, de forte "saturação" demográfica, de problemas alimentares de difícil solução, num território com altíssimas densidades populacionais que, no período colonial, sob administração belga, era possível aligeirar através de migrações para a actual RDC, ex Congo Belga. 
Calas (1999) refere diversos trabalhos de geógrafos sobre a região dos Grandes Lagos (onde desde finais da década de 50 se têm registado situações de grande violência), nos quais se dá grande enfoque à questão demográfica. Embora aquela constitua um aspecto relevante, agindo a montante, no desencadear da grave crise social e política que culminou nos combates e atrocidades de 1994, não pode ser vista só por si como a causa do genocídio ruandês, extremamente intrincado nas suas motivações para se reduzir a uma explicação unilateral.

No diversificado domínio das ciências sociais também são numerosos os estudos e teorias elaborados sobre o assunto. A maior parte dos trabalhos debruça-se sobre a questão, sempre complexa, da identificação dos factores próximos e remotos, internos e externos, que se conjugam a várias escalas, para motivar a eclosão de conflitos armados, na perspectiva da sua prevenção e resolução; na essência, trata-se de tentar encontrar quais as suas "raízes" profundas, as vicissitudes que os precederam e acompanharam o seu desenrolar num dado contexto internacional, aspectos fundamentais para dar corpo a medidas eficazes e acções realistas no plano da resolução. Desta forma, evitar-se-ia a aplicação de "receitas únicas" de pacificação que frequentemente se têm revelado pouco credíveis.

$\mathrm{Na}$ literatura relacionada com o assunto é possível encontrar referências a múltiplas causas sempre inter cruzadas, entre as quais: heranças do passado colonial, desde a fase do tráfico de escravos à de dominação imperialista, nos seus múltiplos aspectos; crise do Estado pós colonial, importado e não legitimado internamente, relacionada com mudanças na configuração das conjunturas e da divisão internacional do trabalho; ingerências externas num contexto de crescente globalização; manipulação de clivagens étnicas ou religiosas; pobreza e baixo desenvolvimento humano, com aprofundamento de grandes desigualdades sociais, o que "permite aos mais ricos comprar armas e obriga os mais pobres a venderem-se" (Bouquet, 2008); cobiça de recursos, factor que, nos últimos anos, graças aos trabalhos de economistas ao serviço do Banco Mundial, entre os quais os de P. Collier et al., (1999, 2000, in Zeleza, 2008:18-20) têm tido grande aceitação, não só no plano científico mas também entre os operadores e agentes da prestação de ajuda internacional.

\section{VELHAS OU NOVAS GUERRAS?}

Ainda no plano geral coloca-se uma questão que tem sido objecto de certa controvérsia: será que, actualmente, as guerras africanas correspondem a um tipo novo de conflito, a "novas guerras", segundo a leitura de muitos geopolíticos (Kaldor, 1999)?

Com o fim do mundo bipolarizado, vários autores afirmam que se verificou uma transformação na natureza dos conflitos. De confrontos de base ideológica, opondo exércitos regulares a uma guerrilha mais ou menos organizada, sustentados por apoios internacionais poderosos, ter-se-á passado a um tipo novo de guerra: surgindo no quadro interno dos países, envolvem grande número de actores, públicos e privados (rebeldes, milícias, mercenários, traficantes, senhores de guerra), recobrindo as lógicas próprias da globalização, relacionadas com a informalidade e o transnacional; desenrolam-se muitas vezes de forma descontínua no tempo, com fases e picos de intensidade diferentes; suscitam a criação de focos territoriais de grande tensão que contrastam com áreas de relativa acalmia e acabam frequentemente por se regionalizar, extravasando para lá das fronteiras políticas, criando "sistemas de conflitos" (Marchal, 2004) que desestabilizam áreas bastante vastas, sem que por vezes, se identifiquem claramente motivações e pro- 
tagonistas. Estas características que, segundo Kaldor (1999), traduzem formas de "globalização subalterna" (isto é, relações profundas entre estados vizinhos devidas à transnacionalização e informalização de fluxos económicos e humanos, permitindo difundir imaginários e mobilizar actores não estritamente nacionais), implicam que a sua análise tenha de integrar as dimensões regionais e mesmo transnacionais.

Outros aspectos mencionados como particularizantes das "novas guerras" dizem respeito às motivações - os discursos ideológicos, que só persistem nas etiquetas dos movimentos em luta (Movimento de Libertação do Congo, Movimento Patriótico da Costa do Marfim...), rapidamente dão lugar a práticas de violência incontrolada, a manifestações criminosas e predatórias; à falta de apoio popular; ao facto de afectarem sobretudo civis; à inexistência definida de "linhas" da frente ou zonas de insegurança (durante a Guerra Fria os movimentos opositores "resguardavam-se" em "santuários", à partida inatacáveis, porque fora das fronteiras políticas); à incorporação de segmentos muito jovens da população (os meninos soldados).

Mas será que se pode de facto falar de um novo tipo de conflituosidade?

Para muitos críticos do paradigma das "novas guerras", também designadas por "guerras pós modernas" ou de " $3^{a}$ geração", estas não são mais do que uma amálgama de velhas guerras (Henderson e Singer, 2002; Kalyvas, 2001 in Zeleza, 2008), salientando-se que não há evidências de "rupturas fundamentais" entre umas e outras. Refira-se, por exemplo, que, nalguns países, nos conflitos que precederam a independência se sobrevalorizou a componente ideológica minimizando-se os efeitos de predação, o fenómeno da incorporação de crianças, as clivagens políticas internas que já estavam presentes (Foucher, 2006).

E a "guerra contra o terror", termo introduzido no discurso político dos EUA na sequência dos atentados de 11 de Setembro, não representará um tipo novo de conflito? Sobre esta questão as opiniões dividem-se. No plano analítico dá-se a ideia de que existe um inimigo único e transnacional.

Mas quem são os combatentes e os inimigos? Como definir a identidade de um terrorista? São actores dentro de um estado, ou do exterior? A tendência é considerá-los exteriores ao estado e referir os estados como patrocinadores do terrorismo. Quais as motivações? Que espécie de guerra? Se é uma guerra, deve ser vista no âmbito das convenções internacionais, mas o tratamento dos prisioneiros de Guantánamo mostrou que não. Quais os respectivos quadros espacial e temporal? Quanto às causas, estas são igualmente difíceis de precisar. Os grupos envolvidos são dispersos e têm um leque de motivações muito vasto.

Argumenta-se que o "terrorismo" veio substituir o comunismo como novo inimigo, o que permite alimentar uma permanente economia de guerra e produz, necessariamente, nacionalismos e patriotismos na nova era global. A atenção dada pelos EUA ao continente africano, no quadro geopolítico pós 2001, tem a ver com a difusão do Islão militante, com a vulnerabilidade de determinados estados encarados como "santuários" de redes "terroristas" globais e com a necessidade de recursos energéticos seguros localizados no exterior do Médio Oriente. Esta viragem não trouxe porém benefícios tangíveis aos africanos: apenas certos aumentos de investimento ou algum apoio aos seus interesses fundamentais de desenvolvimento e democratização. Todavia os efeitos perversos são vários. Em muitos países, através de legislação visando a segurança, em que se dá prioridade a acções anti terroristas, minam-se os direitos humanos internacionais: facilita-se a impunidade, as prisões arbitrárias, a detenção e a tortura, estrangulam-se os direitos dos refugiados e dos que pedem asilo, limitam-se a liberdade de associação, de 
expressão, de reunião e a privacidade, dando uma nova possibilidade à discriminação racial e à intolerância religiosa (Lumina, 2008: 181-199). Estas circunstâncias condicionaram o surgimento de novos conflitos ou o reacender de outros, opondo muçulmanos a cristãos; afectaram receitas do turismo e desviaram recursos para programas de defesa e segurança. Por exemplo, no Corno de África, a "guerra contra o terror" estimulou antigas rivalidades e conflitos e deu cobertura a regimes autoritários desacreditados, como o da Etiópia. Insinuando-se junto dos EUA, aquele país conseguiu "almofadar" a sua afectada reputação internacional a seguir às pouco fiáveis eleições de 2005, atacando o movimento União dos Tribunais Islâmicos, acusado de ter ligações com a Al-Qaeda e que controlava grandes áreas da Somália.

Se o continente quer passar de " um peão a um jogador global, realizando o sonho dourado do pan-africanismo, do desenvolvimento, da democracia e da integração regional", aquelas tendências terão de ser revertidas (Lumina, 2008).

\section{MULTIDIMENSIONALIDADE DAS CAUSAS DOS CONFLITOS ACTUAIS}

Numa perspectiva de enquadramento histórico Zeleza (2008) e Mazrui (2008) põem em evidência que não é possível encarar as guerras africanas de forma isolada. Sem subestimar o forte impacto em matéria de perdas de vidas, Zeleza aponta que, no continente e no decurso do século XX, os 180 milhões de mortos estimados não têm dimensão comparável aos totais registados noutras regiões do mundo, mencionando em particular os muitos milhões provocados quer pela Segunda Guerra Mundial, quer pela revolução soviética ou pela maoísta.

Contudo estas afirmações, e todas as que se baseiam na contabilização de vítimas das guerras, devem ser vistas com prudência. Qual o rigor dos cálculos feitos? Que critérios foram retidos na avaliação contabilística apresentada? Que vítimas? Militares, civis? Mortos em combate, apenas? Como se identifica uma guerra em relação a um conjunto de confrontos de guerrilha ou insurreições pontuais, registados durante um certo período de tempo, mais ou menos longo? Como é possível comparar custos em vidas, em períodos históricos diferentes? Quais as armas utilizadas?

Relativamente ás posições doutrinais em matéria de interpretação dos conflitos armados violentos em África, aqueles autores salientam que cada caso é um caso, embora os respectivos substratos geopolíticos tenham muitos pontos comuns. Analisá-los, numa perspectiva dialéctica, pressupõe que se estabeleçam constantes interligações, complexas, imbricadas e multidimensionais, entre um conjunto de factores internos, (sociais, económicos, culturais, políticos), marcadores das especificidades das situações locais e das suas histórias, e uma multiplicidade de factores externos, identificáveis a várias escalas (locais, nacionais, regionais e transnacionais), consequência da evolução da globalização.

\section{As heranças do passado}

A maioria das contribuições apresentadas no trabalho que serviu de base à análise em presença, confere grande importância explicativa ao peso de um passado de violência. Remontando ao tráfico de escravos, prolongou-se no período colonial, marcando profundamente a memória colectiva dos africanos: "enquanto as guerras mais letais ocorreram entre populações negras, as suas "raízes" ligam-se a um legado branco" (Mazrui 2008: 36). 
Kastfelt (in Zeleza, 2008: 1) reforça esta ideia: "a região que se estende desde o sul do Sudão, passando pelo norte do Uganda até ao Ruanda, Burundi e RD Congo, tem longa história de cultura de terror, de violência sob diferentes formas - tráfico esclavagista, trabalho escravo nas plantações - aspectos que têm de ser equacionados para explicar o presente".

Um outro legado do colonialismo, recorrentemente questionado, relaciona-se com a artificialidade das fronteiras. No entanto, há pouca evidência prática quanto ao papel da disputa fronteiriça como despoletador de tensões entre estados no pós Guerra Fria. As fronteiras, actualmente, são quase sempre espaços onde o Estado está cada vez menos presente; correspondem porém, em muitas secções, a áreas activas, permeáveis, onde florescem diferentes tipos de tráficos lícitos e ilícitos, que retiram até vantagens da existência dos traçados herdados.

Desde 1964, na sequência da primeira vaga de independências políticas, no âmbito da OUA (desde 2000 UA - União Africana) reafirmou-se a intangibilidade das fronteiras. Posta em causa, sem sucesso, na guerra do Biafra (Nigéria) em 1966, ou alimentando litígios ligados a processos de rectificação (por exemplo, entre o Burkina Faso e o Mali em 1974; entre a Mauritânia e o Senegal, de 1989 a 1990), aquela disposição foi quebrada com a separação da Eritreia em 1993 e constitui motivo de tensão latente e de conflito armado (1998) entre este país e a Etiópia.

Todavia, é na economia política do colonialismo que, segundo Zeleza (2008:15), se enraízam muitas das guerras civis actuais. Ainda assim, aquele autor sublinha que na interpretação das mesmas não se pode minimizar, a interferência do tipo de dinâmicas que suscitaram e caracterizaram a inserção das "Áfricas" na fluida ordem global pós colonial e neoliberal, entre as quais a formatação e estrutura dos estados nascidos da descolonização: "os poderes coloniais destruíram velhos métodos de resolução bem como instituições políticas tradicionais sem terem criado outros que efectivamente os substituíssem; geraram-se por isso situações diversas de desordem social e política. Com a independência, nasceram estados frágeis com pouca experiência governativa, legitimados à partida externamente sem o terem sido pelas populações do seu território".

Esta questão tem sido bastante enfatizada na discussão sobre a génese dos conflitos actuais: "o verdadeiro motor é a luta política em torno do estado e foram as condições destas lutas que se modificaram no tempo" (Fall, 2006: 111). Henderson (2008: 51-70) defende também, com base num modelo analítico muito teórico (que vale o que um exercício de correlação vale), que a partir da Segunda Grande Guerra a maior parte dos confrontos eclodiu em relação com aspectos domésticos, de natureza política (tipo de regime), económica (nível de desenvolvimento) e cultural (polarizações étnicas), em países cujas elites se revelaram incapazes de responder ao duplo desafio da construção do estado e da nação. Trata-se porém de perspectivas redutoras, porque minimizam o impacto de factores exógenos, impossíveis de negligenciar no mundo actual.

\section{Conexões regionais e dinâmicas globais}

Contrariamente a uma ideia largamente mediatizada - a da marginalização do continente no quadro mundial - as "Áfricas" estão estreitamente conectadas com as redes da economia política global, embora nem sempre de forma positiva - isto é, com incidência no real desenvolvimento e segurança das pessoas. Na maior parte das vezes aquelas ligações estabelecem-se através de redes criminosas, sobretudo de comércio 
ilegal de recursos naturais ou de armamento, o que contribui, exacerba ou prolonga mesmo as situações de conflituosidade. Mas também muitas outras, ditas legais, por exemplo ligadas à realização de IDE (investimento directo estrangeiro), podem não ser eficazmente conduzidas ou suficientemente monitorizadas, de modo a garantir os direitos humanos e a produção de bem-estar à maior parte da população. Esta realidade confere grande importância ao estudo das conexões existentes entre factores internos e externos, influentes na instigação, facilitação, agravamento e prolongamento dos conflitos.

Alguns autores, como Chabal e Daloz, 1999 in Mclean, 2008: 169, dão maior relevância explicativa aos factores internos ligados à construção histórica da vida social africana: "a desordem é um instrumento político em África e a violência, como veículo para alcançar objectivos políticos, age de acordo com aspectos da cultura política africana em que sobressai o "respeito" pela ostentação do chefe".

Mclean (2008) admite que "é razoável assumir que o comportamento de certos líderes políticos (por exemplo o falecido Mobutu Sese Seko) possa ter contribuído para criar uma situação encorajadora da guerra civil. Citando Regher, afirma que não é a pobreza em si que conduz à guerra mas sim sentimentos de injustiça social e de falta de equidade: aquela surge como resposta social explosiva à crescente "criminalização dos estados". Porém acentua que, embora tratando-se de uma visão importante a reter, é de natureza "afrocêntrica": sobrevalorizando o mau funcionamento do estado, restringese a causas internas, obscurecendo o papel das relações externas na evolução das estruturas sociais e dos modelos de governança, bem como o das relações entre guerras recentes e globalização.

Esta interpretação é igualmente defendida por Clapham, 1996, 2001 e Bayart, 2000, 2004, in Mclean, 2008: 169. Ao contrário de Chabal sustentam que o principal factor no desenvolvimento de relações patrimoniais, são as intervenções internacionais/globais. As estratégias de extraversão, adoptadas pela maior parte dos líderes africanos na sequência das independências, posicionou-os na "interface", política nacional - economias políticas internacionais, com o objectivo, mais ou menos explícito, de sustentar o regime ou, em determinados casos, de acumulação pessoal.

O período da Guerra-fria ofereceu oportunidades para tais práticas, dado o empenho das superpotências em definir "suportes aliados". Com o seu fim, o interesse dos actores externos declinou; mas, em países com governos plenos de debilidades e fortes desigualdades sociais, em que o acesso ao poder é a principal forma de fugir à pobreza, novas estratégias de extraversão puderam corporizar-se, tais como alargamento sem precedentes dos mercados, inovações tecnológicas, avanços nos sistemas de comunicação que facilitam fluxos de mercadorias, de pessoas, de capitais...Na nova conjuntura, actores estatais e não estatais (notáveis, militares, empresas, senhores de guerra...), têm agora oportunidade de usar, ampliar ou mesmo transformar as redes transnacionais em redes de pilhagem, de corrupção, de crime, de violência, reveladoras do "lado negro" da globalização, as quais permitem alimentar e fazer perdurar muitas guerras civis. Destaquem-se as possibilidades oferecidas ao comércio de armas (controlado até ao fim da Guerra Fria mas posteriormente banalizado) e ao "comércio" de homens (mercenários), em relação com a mobilidade acrescida das pessoas.

Nesta perspectiva, quaisquer acções determinadas na resolução dos conflitos violentos que afectam muitas regiões do continente, precisam também de mobilizar redes globais, mas de natureza diferente das que subjazem às situações de guerra, cujos efeitos positivos se começam a detectar. Este facto não implica que se negue o papel central 
que os africanos têm de assumir na determinação do seu próprio futuro, nem anula o argumento de que as culturas e tradições africanas são importantes para estabelecer estruturas relevantes de governança, não obstante as consequências visíveis da globalização na mudança de comportamentos sociais e na proliferação rápida de uma "sociedade civil” global.

\section{Guerras pelos recursos?}

Como se disse no início, no debate recente sobre as causas profundas dos conflitos africanos, tem - se dado grande relevância ao significado dos factores económicos. Esta corrente interpretativa, largamente influenciada pelos trabalhos de Collier et al., (2000), enfatiza que, no cerne dos mesmos, e em particular num continente reconhecido pelas suas riquezas naturais, se encontram principalmente motivações ligadas a ambições e interesses desmedidos de cariz económico (greed), definidos em função de determinadas agendas, mais do que ressentimentos políticos, de natureza ideológica (grievances). Enquanto grande número de analistas refere a escassez e a desigual distribuição de recursos económicos, aspectos associados a situações de grande pobreza, e de vincadas assimetrias sociais, como factores passíveis de interferir no surgimento de conflitos e guerras civis, Collier et al., demonstram que não é a escassez mas sim a abundância de recursos o principal motor no despontar de rebeliões: luta-se pelo controlo dos mesmos, não só para garantir auto financiamento mas também dividendos que a sua exploração permite. Estruturar-se-iam assim verdadeiras economias de guerra, parasitárias, ilícitas, predatórias e dependentes de redes criminosas exteriores, envolvendo numerosos e diversificados actores para quem a paz, em muitos casos, é incompatível com a manutenção dos interesses em jogo.

Esta visão da guerra, tem sido amplamente mediatizada como se disse atrás. Se bem que o controlo das riquezas de um país possa constituir-se como fonte de disputa e de confronto, a maior parte dos críticos do paradigma económico acentua que não se pode concluir que a pilhagem dos recursos seja a explicação fundamental.

Pérouse de Montclos (2006: 151), nota que os estudos realizados, "referindo-se às vítimas e às populações em sofrimento, insistiram sobre as funções económicas dos confrontos...Para alguns, os conflitos africanos seriam sobretudo motivados por objectivos de enriquecimento pessoal ou do clã. Trata-se de análises orientadas que dramatizavam e despolitizavam os conflitos armados".

$\mathrm{O}$ apelo feito à comunidade internacional para desenvolver medidas capazes de contrariar o acesso a determinadas matérias primas (caso dos diamantes na Serra Leoa), destinadas a enfraquecer a capacidade militar dos rebeldes, é revelador duma interpretação descontextualizada no plano político: dando maior ênfase a determinados aspectos mais notados, subestima ou esquece outras modalidades possíveis de financiamento.

Também Mkandwire (2008: 106-135), salienta que as argumentações em causa não podem aplicar-se a todas as situações de guerra, as quais teriam de ser sempre enquadradas numa perspectiva histórica. Considera que é difícil admitir que os movimentos rebeldes sejam vistos ou como "agregados de interesses individuais" ou como meras "empresas", prontas para maximizar os lucros e actuar em função de escolhas "racionais", predefinidas. Se não invalida a hipótese de que as riquezas naturais de uma dada região constituam um importante aspecto em jogo, e tanto maior quanto aqueles recursos são estratégicos (petróleo), fáceis de circular (diamantes) ou raros, o seu significado tem de 
ser avaliado no quadro de estados fragilizados, sem meios de compensar clientelas (entre as quais muitas vezes se encontram as forças armadas), ou de garantir condições mínimas de segurança e protecção aos cidadãos: "as insurgências derivam basicamente de aspirações políticas bloqueadas e, nalguns casos, de reacções de desespero" (Chapham, 1998 in Makandwire, 2008: 107).

Aquele autor desenvolve uma interpretação alternativa. Partindo da análise da natureza e composição dos movimentos rebeldes, considera as interacções que se estabelecem entre eles e as características da estrutura e organização social do país, palco onde actuam. A origem urbana da maior parte dos que os integram (uma juventude marginalizada, sem perspectivas de futuro, fácil de conquistar e de envolver em actividades ilícitas, criminosas), sugere que a génese de muitos conflitos se encontra nas cidades, principalmente nas capitais. A cidade, e sobretudo a capital, é a expressão concreta do poder, é um nó de articulação privilegiado com o mundo global, é o local onde mais se sentiram os efeitos da longa crise económica e social, induzida por más políticas e exacerbada pelo impacto dos PAE. No seio das elites, a luta pelo poder, através da mobilização de identidades, gera rivalidades e fracturas étnicas: projectadas nas áreas camponesas, criam uma "mistura explosiva" facilmente incendiada.

Já no que concerne as condições de base do terreno político onde os conflitos emergem Mkwandire refere que os "estados rendeiros" serão os mais vulneráveis à rebelião (porque patenteiam níveis mais elevados de privação do que os exportadores, facto que parece confirmar as teses de Collier). Todavia, não são apenas motivações de cariz económico que conduzem à guerra, encarada por vezes somente na sua faceta mais brutal e de aparente incoerência de objectivos. Há aspectos de natureza política subjacentes: o enquistamento da estrutura social de acumulação nas economias "rendeiras" é agente provocador de violento descontentamento social, sobretudo junto dos mais jovens, sinal visível de negligência económica à escala do país.

\section{INSEGURANÇA ALIMENTAR: INSTRUMENTO E CONSEQUÊNCIA DOS CONFLITOS}

Um aspecto largamente aprofundado pela sua influência no surgimento, mas também na reprodução, dos conflitos recentes no continente diz respeito às interligações que se estabelecem entre os mesmos, a existência de situações de fome e de insegurança alimentar, versus pobreza, da maior parte da população afectada, e a ajuda alimentar de emergência. Estas questões implicam uma reflexão sobre a dinâmica alimentar da guerra e sobre a falência das políticas implementadas pelos governos africanos em favor de uma produção capaz de garantir a segurança alimentar (SA) às suas populações.

O conceito de SA pressupõe, genericamente, que um país, uma região ou as famílias, tenham capacidade de acesso ao consumo continuado de um conjunto de produtos capazes de garantir, de acordo com os respectivos hábitos, uma alimentação equilibrada dentro de níveis desejados. Tal situação depende da interacção de diferentes aspectos de natureza económica, social e política: disponibilidade de alimentos, quer produzidos localmente (o que depende da produção agrícola e respectiva produtividade), quer importados, quer provenientes da ajuda externa; eficazes sistemas de distribuição que coloquem os alimentos acessíveis às populações (o que se prende 
também com os preços fixados); meios de acesso aos mesmos por parte das famílias, tendo em conta os níveis de rendimento e determinados factores sócio-demográficos (dinâmicas de crescimento, composição etária e por sexo, níveis de saúde e de escolarização, normas culturais, hábitos de consumo).

Nas "Áfricas", grande parte das populações, desestabilizadas por guerras civis, vivem e sobrevivem da agricultura, cujo papel na produção de subsistências é relevante, embora insuficiente na maior parte dos países. As práticas agrícolas, não obstante a diversidade regional, são ainda, salvo poucas excepções, de natureza pluvial (e por isso vulneráveis aos aléas naturais), dominantemente extensivas, com baixa produtividade e modesta produção de excedentes.

Segundo dados da FAO, cerca de $1 / 3$ da população africana encontra-se em situação de subnutrição crónica, mesmo em países exportadores de produtos agrícolas, o que se explica sobretudo pela forte incidência da pobreza e consequente falta de oportunidades de acesso a um conjunto de bens básicos, quer materiais (terra, água, sementes...), quer sociais. Estimou-se que a importação de alimentos à escala continental poderia atingir $13 \%$ ao ano em 2008 , de modo a cobrir as necessidades alimentares de uma população em crescimento, dada a insuficiência da produção local.

Sikod (2008: 199-213) e Brunel (2004: 174-181) sustentam que, actualmente, a grave situação de insegurança alimentar de muitos africanos está cada vez mais relacionada com a ocorrência de conflitos; que é cada vez menor a relação entre fome e exposição ao risco climático (caso das regiões saelianas); que as situações graves de penúria alimentar existem cada vez mais em regiões pouco povoadas mas ricas em recursos - "as fomes actuais em África são consequência de lógicas de predação dirigidas contra as populações e de processos de instrumentalização política pelos governos ou por movimentos políticos marginalizados".

As consequências directas e indirectas da luta armada violenta no funcionamentos dos sistemas de produção alimentar são devastadoras: degradação de ecossistemas, destruição de capital físico e humano, desmantelamento das redes de capital social, das associações comunitárias, dos equipamentos e das infraestruturas agrícolas; deterioração da qualidade de vida; fuga das populações; emergência de crimes sexuais e de intimidação suscitando o enfraquecimento da coesão social, porque as famílias perdem alguns dos elementos ou criam ódios entre si...

Por outro lado, as partes em confronto, tirando partido das dificuldades reais das populações, conseguem canalizar em benefício próprio ajuda alimentar de emergência. A partir de relatórios do WFP (World Food Programme) e da Millennium Task Force (Sikod, 2008: 211), constata-se que aquela ajuda, providenciada no decurso de um conflito, pode contribuir para o mesmo e ser usada como arma pelas várias facções. Os testemunhos de quem vive a guerra por dentro, revelam que os alimentos não conseguem, muitas vezes, chegar às populações verdadeiramente necessitadas o que faz germinar tensões e revoltas: em várias regiões, a falta de acesso das organizações humanitárias é mesmo deliberadamente provocada.

Sendo a SA e o desenvolvimento agrícola as duas faces de uma mesma moeda, os dois conceitos apontam no sentido de se aumentar a produtividade agrícola e o rendimento da maior parte das famílias que vivem da agricultura e de actividades com ela relacionadas. Para tal são necessários um ambiente estável, lideranças com visão, uma sociedade civil cooperante, o que, em muitas regiões do continente, é difícil de admitir a curto e médio prazo... Neste contexto, o risco de guerra civil, motivado em parte por deficiente fornecimento de alimentos, continua latente. 


\section{GUERRAS E RELAÇÕES DE GÉNERO: REVISITANDO AS TEORIAS DE F. FANON}

Não obstante a questão das "causalidades" ser dominante na investigação sobre conflitos em África, há temáticas relacionadas com o assunto, menos referidas, mas não menos interessantes e motivadoras, tais como a problemática do género. A imagem largamente difundida da mulher africana, excessivamente "tradicional", sujeita a todo o tipo de práticas adversas e discriminações, minimiza os importantes "avanços" já conseguidos sobretudo a partir dos universos urbanos, no que respeita, por exemplo, ao acesso e disponibilidade de bens produtivos, às decisões em matéria de fecundidade, ou às intervenções na vida familiar. No entanto, e é essencial afirmá-lo, ainda é longo o caminho a percorrer para que consigam de facto beneficiar de todos os direitos da pessoa.

White (2008:136-165) revisita as teorias de F. Fanon (médico psiquiatra, considerado o primeiro teórico revolucionário anti - colonial), datadas dos anos 60. Procura verificar a aplicabilidade das ideias daquele autor às realidades dos conflitos actuais, atendendo sobretudo à situação das mulheres combatentes.

Fanon (que viveu na Argélia e acompanhou o desencadear da luta pela independência deste país) defendeu que havia uma justificação psicológica para a guerra dita de libertação: a necessidade mental de vencer o efeito de uma espécie de complexo de "inferioridade epidérmica", de "uma capitulação debilitadora de identidades", decorrente de processos de subjugação e de anulação impostos pelo colonizador. A violência revolucionária seria o meio para alcançar a sua "saudável" transformação e, apontando a existência de uma "simbiose entre os movimentos de libertação nacional e os movimentos de emancipação das mulheres, cujo estatuto na "ordem colonial" fora particularmente diminuído, conclui que a violência revolucionária da libertação foi terapêutica para os colonizados, incluindo as mulheres. Com efeito, muitas revoluções e governos africanos incorporaram o activismo político feminino e feminista das mulheres africanas no processo.

Todavia, as conexões entre género e conflitos revelam grande complexidade e apresentam significativa variação no tempo e no espaço. As mulheres são simultaneamente vítimas e agentes, sofrendo efeitos contraditórios de capacitação e de inferiorização. Considerando que os conflitos actuais se interligam com as guerras pró-independência, White refere que os escritos de Fanon não dão relevância suficiente a um conjunto de aspectos de natureza psicológica e política relacionados com o género: a mentalidade "androcêntrica", e não de "inferioridade epidérmica", que moldou as mentalidades de muitos homens africanos no período colonial, reforçou-se com a militarização da luta revolucionária e, depois, na sequência das independências, dado que as forças armadas, como instituição, não são neutras sob ponto de vista do género. Desta forma, no presente, exacerbaram-se efeitos negativos sobre muitas mulheres soldados, perpetuaram-se injustiças e situações de desigualdade que, como Fanon predissera, seriam erradicadas.

Com base em diferentes fontes de investigação, entre as quais depoimentos de ex-mulheres combatentes, identifica alguns aspectos, "esquecidos" por aquele autor, que entravaram o reconhecimento da contribuição das mulheres, em situação de igual para igual, nas lutas anti e pós coloniais. Refiram-se, entre outros, a extrema distorção das relações de género que caracterizaram o período colonial e se traduziram em violência; o olhar europeu, manipulador do patriarcado e das estruturas sociopolíticas pré-coloniais 
(por exemplo, as leis dos indígenas de acordo com o "costume", reforçaram aspectos patriarcais na mentalidade dos africanos colonizados); nacionalismos e militarismos de base patriarcal, relacionados com a natureza das guerras (os homens lutaram para fazer reconhecer a sua identidade, valorizando a coragem e o ideal masculino), condicionantes de relações de género em que as mulheres têm papel subordinado; resistência dos homens africanos à transformação de mentalidades. Se normalmente aquelas são vistas como simples vítimas das guerras (e são-no deveras) e não como agentes activos, o seu papel é no entanto relevante (no combate directo, no apoio logístico não oficial, na manutenção das economias de guerra...). Todavia, tal como refere White, a sua participação militar fica frequentemente envolvida em silêncio, porque muitas são recrutadas ou forçadas a integrar os movimentos rebeldes ainda crianças ou muito jovens, contrariando recomendações internacionais.

Citando uma guerrilheira moçambicana (Maria José Artur, Frelimo, 1998) -“ para uma mulher a decisão de envolvimento na guerrilha não se toma com ligeireza. Ela tem muito mais a perder do que um homem" - e outros depoimentos, aponta que, não obstante a guerra ter produzido novas e mais poderosas identidades femininas, as forças militarizadas continuam a ser instituições patriarcais porque mantêm uma divisão sexual do trabalho, em que a maior parte das mulheres ocupa posições secundárias e subordinadas. Mesmo as que intervêm directamente nos combates, são olhadas muitas vezes como "ajudando os homens", não se subtraindo automaticamente a relações de exploração sexual. Contrariamente à ideia romântica do revolucionário que, na sua época, Fanon construiu, a participação feminina nas guerras de libertação e nas contemporâneas, bem mais complexas e difíceis de identificar como "libertadoras", não contribuiu para um mútuo reconhecimento. Assim, "embora a retórica revolucionária sugira que cada participação na revolução é valorizada, não o é certamente de forma igualitária".

\section{SUDÃO, COSTA DO MARFIM E UGANDA: COMPLEXAS ESPIRAIS DE VIOLÊNCIA}

Através do estudo de casos específicos é possível aproximar a complexidade, singularidade e imbricação das motivações impulsionadoras de muitos dos conflitos violentos em África.

\section{A situação no Sudão}

No Sudão, praticamente desde a independência (formalmente proclamada em 1956), tem-se vivido em situação de tensão política e de guerra civil devastadora embora com períodos mais ou menos longos de interrupção. Estima-se que a guerra tenha provocado mais de 2 milhões de mortos, suscitado a deslocação de muitos milhões de pessoas, acantonadas em múltiplos acampamentos provisórios, sobretudo localizados em torno da capital e outras cidades nos quais se nasce, vive e morre em condições de grande vulnerabilidade.

Com uma posição geográfica de encruzilhada entre uma África "branca" a norte, de dominância árabe e muçulmana, e uma África "negra" a sul, onde prevalecem religiões "tradicionais" e penetrou o cristianismo, apresenta grandes contrastes bio climáticos mas também de natureza étnica e linguística (134 línguas vivas, segundo Ali et al., 2002, in Ahmed, 2008: 73). Apesar de actualmente ser um importante produtor de 
petróleo, a maior parte das famílias é pobre, sendo muito acentuadas as desigualdades sociais entre as várias regiões (estima-se que o PIB / habitante nas regiões do sul, onde se localiza a maior parte das reservas petrolíferas, seja cerca de metade do das norte e centro, onde o poder está polarizado).

Diversas análises deste conflito, na perspectiva das teses de Huntington (1999), tendem a apresentá-lo como resultado de "choques de civilizações", de confronto entre dois mundos, cultural e religiosamente diferentes, reflexo das dicotomias existentes no país. Trata-se, segundo Ahmed (2008), duma explicação demasiado simplista que sobrevaloriza aqueles aspectos. Se os contrastes mencionados "militaram contra uma situação de paz, mesmo antes da independência”, nenhum deles é, só por si, suficiente para explicar a guerra que duradouramente afectou o país.

Encontrar as "raízes" mais profundas do continuum de conflituosidade que caracteriza a história do Sudão, é remontar à época da administração anglo-egípcia (18991956). Neste período vincou-se uma grande diferença nas dinâmicas de evolução das populações das regiões do norte e centro e das do sul, estas secundariamente envolvidas na vida política, na partilha das riquezas e no acesso às oportunidades de desenvolvimento. Foram mesmo corporizadas várias disposições (proibição de usar nomes árabes e utilizar o árabe como língua, de migrar para as regiões do norte, monopólio da educação por parte das missões cristãs...), a fim de contrariar a expansão islâmica, que acabaram por as isolar.

Mas, se o colonialismo criou de facto um sentimento de exclusão nas populações sulistas, há outros factos, muitas vezes subestimados, com grande poder explicativo em várias fases do conflito: "para lá das dicotomias, a realidade das estruturas sociais e políticas que caracterizam o mapa social do Sudão de hoje, em particular o papel das elites que assumiram poder, autoridade e controlo de recursos produtivos, a partir da capital ou de centros urbanos regionais, tornou-se um factor chave" (Ahmed, 2008: 78). A multiplicidade das forças e interesses em confronto mostra que não há uma guerra fruto de oposições norte - sul mas antes um conflito complexo em que, a vários níveis e escalas, se manipulam dicotomias e sentimentos de exclusão.

A primeira fase da luta armada pós-independência desenrolou-se até 1972 . No plano de reconciliação, acordado em Adis Abeba, as regiões do sul obtiveram certa autonomia política, situação vista com descontentamento pelas elites árabes. A paz durou cerca 11 anos, mas a degradação da situação económica conduziu à dissolução da administração das regiões do sul e à aplicação de leis islâmicas, ao país no seu todo. Criou-se assim um clima favorável à luta pelo poder por parte de elites sulistas: explorando relações étnicas, conseguiram mobilização popular e agregar alguns movimentos de oposição ao regime instalado, em torno do SPLM (Sudan People's Liberation Movement).

As hostilidades, que atingiram grande violência, ressurgiram em 1983, numa década marcada por dificuldades internas e externas (crise da dívida, corrupção, secas prolongadas, deslocações maciças de população, afluxo de refugiados, crescimento explosivo das cidades, em particular de Cartum...). Em 1989, "numa altura em que se perspectivava a regulação negociada do conflito cujo corolário seria a instalação de um estado laico, um golpe militar levou ao poder a NIF (National Islamic Front), ilustração sudanesa de um fenómeno muçulmano mais alargado, ligado ao ressurgimento do "Islão político radical" (Ferreira, 2000: 103). Nos anos seguintes assistiu-se à multipolarização e multiplicação dos movimentos de contestação ao regime instalado e ao aparecimento de milícias armadas, o que complexificou a situação. Segundo Ahmed, tratava-se de um 
fenómeno sem base popular, ligado à emergência de elites provinciais, compostas principalmente por jovens urbanos, "destribalizados", por políticos destituídos ou exilados, que não encontravam "espaço" de participação na vida económica, bloqueada e controlada pelas estruturas religiosas tradicionais.

Apenas em 2005 se começou a negociar um acordo de paz entre o governo e o SPLM, em que se concedia maior autonomia às regiões do sul, esperando-se pôr fim à mais longa guerra civil do continente... As eleiçõs gerais (2010) podem bem ser consideradas como um teste em relação ao referendo previsto para Janeiro de 2011, no qual os habitantes do Sul decidirão se continuam ou não a fazer parte de um Sudão unificado. Porém, em 2003, tinha-se aberto, na região do Darfour nova área de violência ... Nalguns meios de comunicação social difundiu-se rapidamente uma interpretação simplista: a situação de conflito que eclodira naquela região, mimetizava a que opusera as regiões do sul ao governo central. No entanto, segundo Lavergne (2000) "não se trata de um confronto entre árabes muçulmanos e negros cristãos do sul, mas sim de uma instrumentalização de milícias, constituídas por camponeses proletarizados, formadas pelo regime de Cartum, a fim de controlar recursos petrolíferos no sul, assim como terras agrícolas".

\section{O caso da Costa do Marfim}

$\mathrm{Na}$ Costa do Marfim, onde os confrontos violentos se desencadearam a partir de 2002, na sequência de um golpe de estado militar que depôs Konan Bédié, sucessor do primeiro presidente pós - independência, Félix Houphouet-Boigny (FHB), falecido em 1993, Akokpari, tal como Ahmed no caso do Sudão, dá grande relevância à interferência das elites políticas no surgimento do conflito. O papel das mesmas na perspectiva de controlo do poder evidencia-se através da manipulação do conceito de cidadania, explorando a dicotomia, cidadão autóctone e estrangeiro residente, entre quem é ou não é "pertença" de um dado território e, por esse facto, tem ou não tem direitos legítimos a auferir da partilha dos recursos nele existentes. Esta questão colocou-se paradoxalmente num país com grande diversidade etnolinguística que, ao longo da sua história, foi local de acolhimento de importantes movimentos migratórios; em que, durante cerca de 4 décadas, o governo forte de FHB, através da intimidação, do suborno, mas também da negociação e do clientelismo, conseguiu captar os principais opositores, assegurar a estabilidade e a convivência étnica. País que, nos anos de 60/70, foi citado como um bom exemplo africano em matéria de desenvolvimento, tem hoje uma economia e uma sociedade fortemente desestruturadas e um território dividido em dois conjuntos - as regiões do norte e centro e as do sul - separados por uma "zona de segurança", controlada por forças internacionais.

Neste quadro de referências, como se poderá explicar a ruptura das condições de estabilidade conseguidas, pelo menos na aparência, durante a governação de FHB, facto que está no cerne dos combates que eclodiram?

Akokpari destaca a importância combinada dos seguintes aspectos: herança colonial, fragilidade do estado pós colonial, e um conjunto de factores externos ligados à dinâmica e às particularidades das conjunturas internacionais. Chamando a atenção para o processo de formação do Estado e para o traçado das fronteiras herdadas, refere que a delimitação fronteiriça se verificou independentemente do processo de formação de um território, de um estado-nação. Na Europa a formação complexa de territórios resultou da história das formações sociais e a fixação das fronteiras materializou as etapas finais. 
Em África a fronteira "surge no seio de espaços que durante muito tempo funcionaram na base da fluidez da vida de relação, como a única linha materializável, se bem que nem sempre materializada. As descontinuidades criadas mudaram as relações pessoas/ espaço, impondo um esquema binário de inclusão/exclusão. Esta postura cria fracturas no sustentáculo de uma vivência em conjunto, condição que levanta o problema da legitimação territorial" (Pourtier, 1996).

$\mathrm{Na}$ Costa do Marfim, tal como noutros países, o conflito irrompeu quando o estado herdado falhou na gestão da sua diversidade e na satisfação do contrato social com os seus cidadãos. A polémica questão da cidadania surgiu apenas nas últimas décadas, no início dos anos 90, centrando-se no conceito de marfinidade, objecto de debate académico. Revelador de uma retórica xenófoba e nacionalista, valorizando as características do legítimo marfinense, na base dos laços de sangue e do local de nascimento, procura identificar, e separar, quem estava ou não legitimamente capacitado para ter acesso aos recursos do país, em particular a terra. Esta posição doutrinária implica, como corolário, a recusa do "outro", do estrangeiro ou de quem é considerado como tal (nestes incluem-se muitas das populações vivendo no território desde longa data com origem imigrante, sobretudo nas regiões do norte; em 1998 aquelas representavam cerca de $26,3 \%$ da população, das quais $75,6 \%$ tinham raízes no Burkina Faso e no Mali).

As motivações deste discurso são simultaneamente de natureza económica e política. Por um lado, argumentava-se que os estrangeiros eram demasiado numerosos no país, sobretudo nas regiões do sul, competindo, no acesso aos recursos, com aqueles que legitimamente tinham direito a eles. Desta forma excluíam-se dos direitos de cidadania as comunidades de origem migrante. Por outro lado, esta argumentação socioeconómica permitia concretizar ambições políticas de determinadas personagens, dado que possibilitava a desqualificação e consequente exclusão de opositores. Como se explica esta viragem no modo de olhar dos imigrantes? Onde se encontram os germens da crise marfinense?

De acordo com a maioria dos estudiosos do tema, tem de se recuar no tempo para compreender a agudização das tensões que se manifestaram violentamente após o falecimento de FHB (1993). Desde 1980 que se foram avolumando dificuldades económicas com as respectivas sequelas políticas (a quebra dos preços das principais produtos de exportação - café e cacau - traduziu-se por graves problemas financeiros, particularmente sentidos nas regiões do sul, onde se estruturara um modelo económico de plantação, agro exportador, envolvendo muitas famílias de origem migrante). A deterioração da situação, com o empolamento da dívida externa e posterior subordinação do país às políticas sob supervisão do FMI, com a crise do próprio Estado, agora privado dos benefícios obtidos através das rendas, que acumulava e utilizava para manter clientelas e "servidores obedientes", teve sérios impactos negativos para a maior parte da população, provocando turbulência e contestação popular.

No plano político, a estratégia do velho Presidente, consistiu em priorizar o individual sobre o colectivo: conseguindo assim gerir a diversidade étnica do país sem conflito, criou profundas tensões internas. Se relativamente à cidadania, esta era adquirida pela residência (o que igualava em direitos todas as populações, entre as quais os imigrantes, mesmo não nacionalizados), já no plano sociocultural definiu-se uma ideologia que conferia ao grupo Akan (Baoulê), ao qual pertencia FHB, maior importância e privilégios, numa estrutura hierarquizada da sociedade. Na base ficavam os dioula, muçulmanos, designação genérica, construída para identificar segmentos populacionais 
amorfos, diversificados étnica e religiosamente, sobretudo imigrantes estabelecidos no país no decurso do tempo. Apesar das situações de exclusão decorrentes da estrutura citada, FHB manobrou habilmente um sistema de compensações a membros das comunidades marginalizadas que lhe garantiram lealdade e permitiram manter a estabilidade no país.

Após a sua morte, num quadro multipartidário, mas numa conjuntura de crise, a competição pelo poder, provocou a crispação do jogo político: impôs-se um discurso fracturante, manipulador das contradições preexistentes, utilizando a noção de marfinidade, o qual, apoiado pelos media, incendiou as relações entre grupos populacionais. Em 2000 foram mesmo referendadas alterações à Constituição no que concerne às cláusulas vigentes da cidadania: no artigo 35 ficou expresso que qualquer candidato a presidente da República, deve ser um marfinense de origem, com pai e mãe também nascidos no país. A entrada em vigor destas novas disposições coincidiu precisamente com a ocorrência da rebelião de 2002, liderada por movimentos nortistas, que lançou o país em grande desordem.

A negação da cidadania a certos grupos, seja em que base for (e a utilizada era bastante ambígua), suscita quase invariavelmente conflito, porque os excluídos procuram reabilitar a sua inclusão política ou provocar a secessão territorial. Permitindo leituras simplistas sobre o lugar legítimo dos estrangeiros e dos nacionais, contribuiu para uma regionalização que rapidamente se transformou numa etnicização do campo político. Os confrontos entre forças governamentais e movimentos rebeldes, que se assumiam como representantes de grupos de populações historicamente marginalizadas, em grande parte com origem migrante, e que se acantonaram nas províncias do norte, traduzem o desenterrar das contradições políticas do país. Alastrando noutras regiões, denunciam as crescentes tensões e suspeições acumuladas entre as diferentes comunidades, contra todos os que se julgam exteriores a um dado território (Banègas, 2002). Os variados esforços feitos no sentido da reconciliação, que culminaram nos acordos de Ouagadougou, em 2007, procuraram reverter as contradições geradas, de forma a garantir a estabilidade necessária para o bem-estar das populações. Foi criado um governo de transição, onde estão representados os principais movimentos rebeldes, com a difícil missão de proceder ao desarmamento e preparar eleições, até hoje sistematicamente adiadas, tendo-se decidido a retirada progressiva das tropas estrangeiras presentes no sul do país. No entanto, permanece a desconfiança entre as partes, que trocam acusações mútuas. Será que a paz interessa verdadeiramente a quem a discute? Haverá de facto intenção de a alcançar?

\section{As guerras no Uganda}

O ciclo vicioso de guerras longas e violentas que, praticamente desde a independência (1962), se tem vivido no Uganda, nas regiões do norte e leste, com graves violações dos direitos humanos, deixou um conjunto de feridas profundas, muito difíceis de cicatrizar: milhares de mortes, em grande parte civis, incorporação nos grupos armados de numerosas crianças, muitas delas raptadas, incentivadas a praticar a violência, destruição de gerações de jovens, milhões de pessoas deslocadas, degradação e ruína de infra estruturas...

Ainda hoje, não obstante o acordo de cessação de hostilidades de 2006, persistem situações de tensão, de marginalização económica e social, estando por resolver imensos problemas de reparação de danos morais sofridos por uma multidão de vítimas, entre as quais muitas mulheres e crianças, estas nascidas na guerra, sem qualquer relação fami- 
liar...Em 2003, admitia-se que cerca da $63 \%$ da população residente naquelas regiões vivia abaixo da linha de pobreza nacional, valor bem superior à média do país $(37,7 \%)$.

No entanto, o Uganda, desde meados da década de 90 , foi reconhecido, pelas grandes instituições internacionais e muitos países dadores, como exemplo de bom desempenho, em matéria de realização de reformas económicas, de desenvolvimento humano, de estabilidade e de governação. De acordo com os dados mais recentes do PNUD (Programa das Nações Unidas para o Desenvolvimento 2007-2008), integra o lote de países considerados de "desenvolvimento humano médio", isto é, com um IDH (índice de desenvolvimento humano) superior a 0,5. Como é possível conciliar tal rótulo com situações de estagnação económica e tensão latente numa parte do país, que se encontra envolvida directa e indirectamente em conflitos regionais? Poder-se-á de facto designar o Uganda como um estado democrático e emergente, quando a desagregação a nível regional do valor do indicador acima referido, mostra que a história oficial de sucesso é apenas apanágio das regiões do sul? Quando a resiliência da violência é uma realidade numa fracção do seu território?

As questões subjacentes às interrogações colocadas foram detalhadamente estudadas por Shaw et al., (2008: 214-238). Recuando no tempo, constata-se que os percursos complexos e contraditórios do conflito ugandês, mergulham na história - " a origem dos conflitos é profundamente geográfica: resulta de uma organização do território fundamentada numa construção/manipulação étnica arquitectada pelo colonialismo britânico (1890 - 1962). Uma "antropologia prática" foi aplicada no enquadramento e na valorização do território e depois na definição das condições da independência...O Uganda foi vítima do fascínio que o Buganda (reino forte, localizado a sudoeste, bem organizado e conquistador, em luta constante contra o Bunyoro do norte) exerceu sobre os britânicos, do estatuto privilegiado que lhe foi reconhecido, dos efeitos deste favoritismo e do "sub-imperialismo" baganda daí resultante" (Dubresson et al., 1998: 308). Segundo a Constituição federal de 1962, o Buganda conservaria as suas estruturas de estado e o exército, num país que juntava 4 reinos antigos, mas em que se consagrava no kabaka (rei do Buganda) a presidência vitalícia e hereditária. Esta situação continha os germens de todos os problemas futuros.

Desde 1966, data em que aquela Constituição foi abolida, a vida politica do país foi marcada pela instabilidade e pela violência, sendo de referir a década de 70 , correspondente ao governo do general Idi Amin Dada: durante cerca de 8 anos o país, considerado no início do século XX como a "pérola" das colónias britânicas, transformou-se num "reino de terror", em que o recurso aos assassinatos a mando se tornou modo de regular diferendos pessoais. Todavia, após a queda de Amin em 1979, a situação não mudou muito, apesar da fachada politica e apoio das instituições financeiras internacionais: pelo contrário, a violência e os acertos de contas foram igualmente prática do quotidiano, com consequências desastrosas nos planos político, cultural e económico (Dubresson, 1998: 308-319).

O golpe de estado de 1985, levou ao poder Y. Museveni, ainda hoje presidente (reeleito em 2006 no âmbito das primeiras eleições pluralistas), que assumiu a árdua tarefa da reconstrução do país. Conseguindo relativa estabilidade, mobilizando energias e talentos, empreendeu diversas reformas económicas impostas pelo FMI e Banco Mundial no quadro de parcerias múltiplas, com forte aplicação de investimento estrangeiro e local (graças às diásporas, fenómeno recente e relacionado com a fuga às atrocidades cometidas na era Amin). A abertura dos doadores internacionais, a participação do país em inúmeras iniciativas, a acção de numerosas ONG's, contribuíram também para o franco crescimento 
económico registado, para a realização de progressos significativos em matéria de desenvolvimento humano, de redução do deficit e da inflação, o que foi saudado positivamente por aquelas instituições. Porém, este contexto de sucesso tem a sua face negativa: grande arbitrariedade nas decisões, crescimento exponencial da corrupção, dos tráficos ilícitos, da violência política com marginalização das regiões do norte e de parte do centro, o que agravou uma dicotomia interna já existente. Naquelas, praticamente desde os fins da década de 80 , tinham voltado a eclodir confrontos e guerra de guerrilha, entre as forças governamentais e movimentos rebeldes (entre estes destaca-se o designado "Exército do Senhor" - LRA - cujas motivações não são claras, reunindo muitos militares desmobilizados nos regimes anteriores).

Se para interpretar a evolução registada, que se saldou na divisão do país em dois conjuntos territoriais - as duas Ugandas - é determinante recorrer a factores herdados do colonialismo, Shaw et al., salientam a necessidade de se ponderar a interferência de outros aspectos, dado que as definições e relações entre sociedade civil, economia e estado estão em constante mudança.

Nas últimas décadas, na construção do cenário de progresso apresentado pelo país (pelo sul do país), foram decisivos os efeitos das dinâmicas próprias da globalização, actuantes aos níveis local, nacional, continental e global, ideia que reforça as teses já comentadas atrás, retirando vantagens da posição geoestratégica do país como placa giratória de trocas formais e informais de diversas mercadorias (coltan, diamantes, ouro, armas, capital, franchise, tecnologia, esta sobretudo proveniente da África do Sul, na sequência do fim do apartheid, mas também de outras regiões do mundo).

Não obstante as dificuldades sentidas na obtenção de uma solução de paz pela via negocial (que nem o governo nem os movimentos rebeldes mostravam empenho em alcançar, preferindo a via militar), os acordos de 2006 e o plano sobre responsabilidade e reconciliação de 2007, para o relançamento económico e integração das regiões do norte, abriram uma possibilidade de se fazer justiça. Porém, a posição geográfica do país, num quadro regional de guerra, onde acabou por se envolver, a porosidade das fronteiras, a pobreza em que vive grande parte das famílias, a habituação à violência, a desconfiança étnica, a necessidade de violar regras morais para sobreviver, a duradoura intransigência dos governos em encontrar a paz por via do diálogo, são alguns dos muitos aspectos que tornam difícil e problemática a sustentabilidade do "sucesso"...

Nestas condições, atendendo às limitações mencionadas, tal como Shaw et al., concluem, é difícil considerar o país como um exemplo de progresso real, em matéria de desenvolvimento humano e de construção de um verdadeiro estado democrático, dotado de uma política e de um governo representativo e eficaz.

\section{REFLEXÕES FINAIS}

Fazendo um balanço do conjunto das questões analisadas, constata-se que é impossível abranger todas as manifestações e todas "causalidades" - as mais ou as menos distantes, as internas e externas, as objectivas e subjectivas, as económicas e as culturais, as sociais e as políticas - dos conflitos violentos recentes que afectaram e afectam o continente. Cada caso é singular, complexo, multidimensional, dramático, demasiado sério para que seja objecto de explicações simplistas e de soluções gerais na base de modelos universalistas. Como refere Zeleza (2008: 26) "a história mostra-nos que os estados e as sociedades africanas são constelações complexas construídas a partir de 
múltiplos compromissos com o mundo exterior". Nesta perspectiva ganham relevância os estudos de natureza multidisciplinar desenvolvidos numa óptica comparativa, fundamentais para se encontrarem soluções de paz e se definirem medidas de prevenção realmente eficazes e duradouras. É corrente afirmar que, num quadro global, as soluções terão de ser vistas também numa óptica global. No entanto, sem o envolvimento participado dos africanos, através das suas organizações de nível regional e continental, serão sempre soluções exportadas.

Sendo as tragédias humanas que são, as guerras, que se viveram e ainda vivem no continente, num contexto dinâmico de mudança, suscitando processos de decomposição - recomposição dos poderes e dos territórios (Bouquet, 2008), corresponderão, ou não, ao começo de uma dinâmica de evolução, de reestruturação política, económica e estratégica, após as perturbações introduzidas pelo colonialismo e pelos reflexos da Guerra Fria? Será que, de acordo com a expressão de Bayart, se configuram como "um modo de produção do político, mas também como um modo doloroso, violento, mas talvez necessário, de produção de identidades, da nação, da economia...Um modo de entrar numa nova história" (Rufin, 1996:80)? Ou não serão, pelo contrário, processos de decomposição dos Estados, de bloqueio em matéria de desenvolvimento humano e económico, não só devido à destruição provocada nas pessoas e nos bens, mas também decorrente da insegurança na qual se encontram os agentes económicos? (Hugon, 2007: 143). A discussão está aberta...

"A guerra, disse o adivinho, é uma serpente que matamos sem pisar a cabeça. Um pequeno descuido e eis que ela ressurge no escondido do capinzal. Desta volta, porém, para nos envenenar a cobra já nem precisa morder. Basta despertar a lembrança dos venenos que nos correm nas veias ...

Mas a guerra chegou aqui a esta região? indagou Benjamin.

- A guerra entra mesmo onde não chega."

Mia Couto (O Outro Pé da Sereia)

\section{BIBLIOGRAFIA}

Ahmed A (2008) Multiple Complexity \& Prospects for Reconciliation \& Unity. The Sudan Conundrum. In: Nhema A, Zeleza P (Eds) The Roots of African Conflicts. The Causes and the Costs. J. Currey, Oxford: 71-87.

Akokpari J (2008) You Don't Belong Here. Citizenship, the State \& Africa's Conflicts. Reflections on Ivory Coast. In: Nhema A, Zeleza P (Eds) The Roots of African Conflicts. The Causes and the Costs. J.Currey, Oxford: 88-105.

Banègas R, Losch B (2002) La Côte d'Ivoire au bord de l'implosion. Politique Africaine, 87: $139-161$.

Bayart J-F (1989) L'État en Afrique. Fayard, Paris.

Bayart J, Ellis S, Hibou B (1997) La criminalisation de l'état en Afrique. Complexe, Paris.

Bouquet G (2008) Guerres et conflits en Afrique. La décomposition das pouvoirs et des territoires http://fig-st-die.education.fr/actes/actes_2008/bouquet/resume.html, [Acedido em 10 de Março de 2009].

Brunel S (2004) L'Afrique. Bréal, Paris. 
Calas C (1999) Les densités: introduction à la géographie de L'Afrique orientale. Espaces. Population. Societés. 1 : 53-65.

Dubresson A, Marchal J-Y, Raison J-P (1994) Les Afriques au Sud du Sahara. In Brunet $\mathrm{R}$ (dir) Géographie Universelle. Bélin-Reclus, Paris.

Fall G (2006) Les nouveaux risques de conflictualité en Afrique. In Chi D (ed) Les Défis de l'Afrique Dalloz, Paris.

Ferreira P (2001) Conflitos em África. Estratégia - Revista de Estudos Internacionais, 15: 9-11.

Gaud M (2004) L'Afrique entre décomposition et recomposition. Questions internationales, 5: $6-24$.

Henderson E (2008) When States Implode. Africa's Civil Wars 1950-92. In: Nhema A, Zeleza P T (Eds) The Roots of African Conflicts. The Causes and the Costs. J. Currey, Oxford: 51-70.

Hugon P (2007) Géopolitique de l'Afrique. Sedes, Paris.

Huntington S (1999) O choque de civilizações e a mudança na ordem mundial. Gradiva, Lisboa.

Kaldor M (1999) New and old wars. Organised violence in a Global Era. Polity Press, Cambridge.

Lacoste Y (2006) Géopolitique. La longue histoire d'aujourd'hui. Larousse, Paris.

Lavergne M (2000) Le Sudan contemporain. Karthala, Paris.

Lumina C (2008) Legislative Responses to Terrorism \& the Protection of Human Rights. A Survey of Selected African Practice. In: Nhema A, Zeleza P (Eds) The Roots of African Conflicts. The Causes and the Costs. J.Currey, Oxford: 181-198.

Maclean S (2008) Fighting Locally, Connecting Globaly. Inside \& Outside Dimensions of African Conflicts. In Nhema A, Zeleza P (Eds) The Roots of African Conflicts. The Causes and the Costs. J.Currey, Oxford: 166-180.

Makandwire T (2008) The Terrible Toll of Postcolonial Rebel Movements. Towards an Explanation of Violence against Peasantry. In: Nhema A, Zeleza P(ed) The Roots of African Conflicts. The Causes and the Costs. J.Currey, Oxford: 106-135.

Marchal R (2008) De nouveaux modes de règlements des conflits. Questions internationales, $33: 41-49$.

Mazrui A (2008) Prologue. Conflict in Africa: an Overview. In: Nhema A, Zeleza P (Eds) The Roots of African Conflicts. The Causes and the Costs. J. Currey, Oxford : 36-50.

Nhema A, Zeleza P (2008) (Eds) The Roots of African Conflicts. The Causes and the Costs. J. Currey, Oxford.

Pérouse de Montclos M (2006) Les guerres d'aujourd'hui sont plus nombreuses, plus meurtrières, plus prédatrices, plus barbares! In Courade G (coord) L'Afrique des idées reçues. Bélin, Paris:151-157.

Pourtier R (coord) (2008) La géopolitique de L'Afrique et du Moyen Orient. Nathan, Paris.

Pourtier R (2002) Espace et nation en Afrique centrale, la dimension oubliée. In Historiens et Géographes 381: 303-309.

Rufin J-C (dir) (1996) Les conflits en Afrique. Relations Internationales \& Stratégiques, 23: 79-186. 
Shaw T, Mbabazi P (2008) Two Africa's? Two Uganda's? An African “Democratic Developmental State'? Or another "Failed State'? In: Nhema A, Zeleza P (Eds) The Roots of African Conflicts. The Causes and the Costs. J. Currey, Oxford: 214-238.

Sikod F (2008) Conflicts \& Implications for Poverty \& Food Security Policies in Africa. In: Nhema A, Zeleza P (Eds) The Roots of African Conflicts. The Causes and the Costs. J. Currey, Oxford: 199-213.

Voucher V (2006) Conflits d'Afrique, conflits globaux? In Chi D (ed) Les Défis de l'Afrique. Dalloz, Paris.

White A (2008) Fanon \& African Woman Combatant. Updating Fanon's Psycological Perspectives on Anti-colonial \& Post colonial Wars. In: Nhema A, Zeleza P(Eds) The Roots of African Conflicts. The Causes and the Costs. J. Currey, Oxford: 136-165. 